\title{
Contribuições à técnica cirúrgica em transplante renal - Hospital das Clínicas da Faculdade de Medicina da Universidade de São Paulo
}

\author{
Contributions to the surgical techniques of \\ kidney transplantation - Clinic Hospital of São \\ Paulo University School of Medicine
}

\author{
loannis M. Antonopoulos', Affonso C. Piovesan², Renato Falci \\ Jr. $^{3}$, Hideki Kanashiro ${ }^{3}$, Fernando J. Saito ${ }^{3}$, William C. Nahas ${ }^{4}$
}

Antonopoulos IM, Piovesan AC, Falci Jr. R, Kanashiro H, Saito FJ, Nahas WC. Contribuições à técnica cirúrgica em transplante renal - Hospital das Clínicas da Faculdade de Medicina da Universidade de São Paulo. Rev Med (São Paulo). 2009 jul.-set.;88(3) ed. especial:163-7.

\begin{abstract}
RESUMO: Não é infreqüente ouvir que, em transplante renal, inovações de impacto no âmbito cirúrgico já não são mais prováveis. No entanto, soluções de alto impacto econômico ainda surgem com freqüência e muitas delas têm surgido no Brasil, contribuindo significativamente para a mudança de conduta cirúrgica em transplante renal a nível mundial. A técnica cirúrgica do transplante renal propriamente dita está bem estabelecida há anos, sendo muito parecida entre os diversos serviços de transplante. Já no que se refere ao tratamento cirúrgico das complicações do transplante e dos pacientes com doenças associadas à insuficiência renal crônica dialítica (IRCD), observamos considerável controvérsia e variação nas condutas. Este estudo pretende oferecer um panorama sobre as técnicas cirúrgicas utilizadas no transplante renal, as complicações decorrentes deste procedimento e os resultados obtidos pelo Serviço de Transplante Renal do Hospital das Clínicas da Faculdade de Medicina da Universidade de São Paulo.
\end{abstract}

DESCRITORES: Transplante de rim. Procedimentos cirúrgicos urológicos/métodos. Unidade hospitalar de urologia. Insuficiência renal crônica/cirurgia. Hospitais de ensino.

\begin{abstract}
A penas recentemente os pacientes transplantados têm recebido atenção quanto ao rastreamento de doenças não relacionadas à insuficiência renal crônica dialítica (IRCD). Isso acontece, talvez, devido ao fato de os médicos se concentrarem mais no transplante, propriamente dito, devido à necessidade do controle constante dos níveis de medicação imunossupressora bem como da função renal do enxerto.
\end{abstract}

Dois outros grupos de pacientes que merecem menção especial são os pacientes pediátricos e os doadores vivos. $O$ transplante renal em crianças apresenta particularidades cirúrgicas específicas pois, muitas vezes, as doenças que levaram à perda da função renal são malformações do trato urinário. Quanto aos doadores vivos, estes merecem todo o investimento no sentido de tornar seu ato de doação o menos sofrido possível, além de devolvê-los a suas

1. Cirurgião chefe da Unidade de Transplante Renal (UTR) do Hospital das Clínicas da Faculdade de Medicina da Universidade de São Paulo.

2. Cirurgião responsável pelas reuniões científicas dos residentes da UTR Hospital das Clínicas da Faculdade de Medicina da Universidade de São Paulo.

3. Cirurgiões assistentes da UTR Hospital das Clínicas da Faculdade de Medicina da Universidade de São Paulo.

4. Professor titular de urologia da Faculdade de Medicina da Universidade de São Paulo. 
Antonopoulos IM et al. Contribuições à técnica cirúrgica em transplante renal - HC/FMUSP.

atividades normais o mais precocemente possível e com o mínimo de seqüelas.

Às famílias dos doadores falecidos, cabe dizer que este ato de amor ao próximo justifica todo o esforço em melhorar as técnicas de preservação do órgão doado otimizando os resultados do transplante.

\section{Das inovações técnicas}

Em todo o mundo, o número de pacientes que necessitam de transplante renal é muito maior do que o número de órgãos disponíveis. No Brasil, infelizmente, a situação é a mesma. Neste sentido, tudo o que puder ser feito para otimizar o aproveitamento de órgãos, mesmo aqueles considerados marginais, é bem-vindo. Uma das situações que levam o órgão doado a ser considerado marginal é a presença de doenças arteriais no rim em questão. A proporção dos rins provenientes de doadores vivos relacionados ou não relacionados com malformações vasculares pode chegar a até 1,8\% dos transplantes. As lesões encontradas são dilatações aneurismáticas $(27 \%)$, lesões ateroscleróticas $(36,5 \%)$ e displasias fibromusculares $(36,5 \%)^{1}$. O aproveitamento destes órgãos passa pela correção das lesões com cirurgia de banco (backtable) sob hipotermia. Naturalmente, estes casos apresentam riscos relacionados ao transplante e ao uso dos imunossupressores. Numa casuística recente de 11 receptores cujos doadores vivos apresentavam anomalias anatômicas arteriais, nenhum evoluiu com complicações cirúrgicas ou perda do enxerto relacionada à anomalia. Mais importante ainda, num seguimento médio de 88 meses todos os doadores estão bem sem apresentar qualquer complicação.

Outra situação delicada é a manipulação de rins em ferradura, a anomalia mais freqüente de fusão. Estes rins são vascularizados por múltiplas artérias, que não seguem nenhum padrão anatômico, impedindo, frequentemente, a separação das duas unidades renais. Ainda, pode ser feito, com segurança, um transplante renal em bloco, utilizandose uma técnica modificada de anastomoses vasculares e dos ureteres. A modificação da técnica consiste em anastomosar a artéria aorta e a veia cava do doador com os vasos do receptor, ao invés de realizar múltiplas anastomoses. Os ureteres são anastomosados de forma látero-lateral com a bexiga do receptor. Naturalmente, o receptor, para tal situação, deve ser selecionado e de preferência não ser portador de excessiva co-morbidade.

Muitos pacientes, acabam por entrar em IRCD sendo ainda portadores de anomalias anatômicas congênitas ou adquiridas, mais freqüentes na faixa pediátrica. Essas anomalias necessitam de tratamento e, por vezes, reconstrução do trato urinário. São casos complexos pois além de necessitarem de mais de uma cirurgia para adaptá-los ao transplante renal precisam de cuidados adicionais no pós-operatório imediato e por vezes para o resto da vida. O Brasil possui a maior experiência mundial com a reconstrução do trato urinário em pacientes transplantados renais tanto adultos como pediátricos ${ }^{3,4}$. A casuística inicial, publicada em 2002, consiste de 25 transplantes renais em 24 receptores que foram tratados com ampliação vesical. Hoje, contamos com mais de 50 pacientes submetidos a reconstrução do trato urinário inferior e que receberam um enxerto renal. A etiologia da disfunção vesical foi bexiga neurogênica com hiperatividade detrusora em 11 casos (46\%), tuberculose gênito-urinária em 5 casos $(21 \%)$, refluxo vésico-ureteral em 4 casos (17\%), válvula de uretra posterior em 3 casos $(12 \%)$ e cistite intersticial num caso (4\%). Doadores vivos foram utilizados em 17 casos (71\%) e a ampliação vesical foi feita antes do transplante na maioria dos casos (88\%). A ampliação vesical foi realizada utilizando-se o íleo em 16 casos (67\%), segmento íleo-cecal em 2 casos (8\%) e cólon sigmóide nos 6 casos restantes $(25 \%)$. É importante frisar a preferência dos autores pela anastomose do ureter do rim transplantado na bexiga nativa em $67 \%$ dos casos. Quando isto não era possível, a anastomose do ureter transplantado foi feita no segmento intestinal em $25 \%$ dos casos e no ureter primitivo em $8 \%$ dos casos. Os resultados foram excelentes, com $80 \%$ dos rins funcionando por um seguimento médio de 53 meses (variação de 6 a 118 meses). A creatinina sérica média foi de $1,56 \mathrm{mg} / \mathrm{dL}$ (variação de 0,7 a $2,6)$. Três pacientes $(12 \%)$ faleceram por causas não relacionadas ao transplante e um caso ( $4 \%$ ) foi a óbito devido a um adenocarcinoma que se originou na região da anastomose vésico-intestinal. A sobrevida atuarial dos enxertos renais com um, dois e cinco anos foi respectivamente de $96 \%, 92 \%$ e $78 \%$. As complicações incluíram infecções sintomáticas do trato urinário, estenose ureteral e linfocele. Tais resultados mostram que a ampliação vesical em transplante renal é segura e eficaz na devolução da função vesical nos casos de bexigas inelásticas e que o transplante renal pode ser feito com segurança após a ampliação vesical.

Os resultados da reconstrução de bexigas com prejuízo de função utilizando-se segmentos intestinais provaram que esta alternativa é excelente. No entanto, é preciso ressaltar que, mesmo nos casos de sucesso, existem problemas a administrar. Um deles é que os segmentos de intestino produzem muco o que pode atrapalhar o esvaziamento das bexigas ampliadas por obstrução das sondas usadas para 
esta finalidade. A outra limitação é a característica absortiva da mucosa intestinal o que pode provocar acidose metabólica se a função renal decair ou se a bexiga não for esvaziada na freqüência adequada. As bexigas ampliadas com segmentos intestinais e que não são esvaziadas adequadamente podem, com o tempo, sofrer grande aumento de capacidade, o que pode ser inconveniente. Finalmente, como vimos acima, o risco de desenvolvimento de tumores malignos na zona de anastomose vesicointestinal não pode ser desprezado. Para superar estas dificuldades, já foi estudada a possibilidade de utilização do próprio trato urinário primitivo dilatado para a ampliação vesical $^{4}$. Entre 1995 e 2003, 8 pacientes com idades entre 3 e 30 anos com dilatação ureteral e disfunção miccional foram tratados com ampliação vesical utilizando os próprios ureteres dilatados. A etiologia da disfunção vesical foi bexiga neurogênica em 3 casos $(37,5 \%)$, válvula de uretra posterior em 3 casos $(37,5 \%)$ e refluxo vésico-ureteral em 2 casos (25\%). O acompanhamento dos casos com métodos de imagem e estudo urodinâmico foi feito por um período de seguimento médio de 50 meses (variação de 4 a 93 meses). A comparação de parâmetros antes e depois da cirurgia corretiva demonstrou um impressionante aumento da capacidade média da bexiga de 2 vezes o valor original, além de colocar a complacência vesical dentro de valores aceitáveis. A creatinina média foi de $1,65 \mathrm{mg} / \mathrm{dl}$ (variação de 0,8 a 2,5). Nenhum enxerto renal perdeu a função, demonstrando que a ampliação vesical com ureterocistoplastia combina os benefícios da enterocistoplastia sem adicionar riscos e complicações devendo ser a primeira opção sempre que possível.

Como mencionado, o transplante renal na faixa pediátrica apresenta consideráveis desafios. Isto é particularmente verdadeiro para os casos de crianças muito pequenas (pesando 20 quilos ou menos). É freqüente observarmos transplantes feitos em diversos serviços utilizando a via intraperitoneal, com óbvias desvantagens, nos casos fadados a complicações como sangramento e fístulas urinárias. Nos casos em que há hemorragias, a irritação peritoneal pelo sangue complica com dor e íleo paralítico. Nos casos que cursam com fístulas urinárias, o extravazamento de urina no peritônio também causa irritação, reabsorção de excretas e potencial infecção intra-peritoneal. A não abertura do peritônio é útil pois permite a realimentação precoce do paciente, uma vez que a incidência de atonia ileal por esta via é muito menor. Assim sendo, o uso da via extraperitoneal traz a vantagem de restringir o sítio da complicação no retroperitônio diminuindo a incidência de complicações graves ${ }^{6}$. O estudo de 46 crianças com média de idade de 7 anos e pesando 20 quilos ou menos (média de 16,6) demonstrou que esta via pode ser utilizada com vantagens e segurança. Foram feitos 49 transplantes neste grupo de pacientes utilizando incisão em forma de jota partindo da sínfise púbica até o rebordo costal criando-se a loja do transplante por meio do rebatimento medial do peritônio, sem abrí-lo. As anastomoses vasculares, em geral, utilizaram os vasos ilíacos comuns do receptor ou mesmo a cava e aorta de acordo com o tamanho do paciente para evitar desproporção entre os vasos. O período de internação médio foi de 23 dias (variação de 6 a 83 dias) e o seguimento médio foi de 56 meses (variação 12 a 131 meses). Todos os pacientes receberam água por via oral no primeiro dia do pós-operatório sendo realimentados no segundo dia. As complicações observadas foram 2 casos de fístula urinária (4\%), 2 casos de infecção de superficial de parede (4\%) e 3 casos de complicações vasculares $(6 \%)$ sendo um caso de trombose venosa, um caso de estenose de anastomose arterial e um caso de "kinking" arterial. Apenas um enxerto (2\%) foi perdido por complicação cirúrgica. Assim sendo, além das vantagens descritas acima, o uso desta via nesses pacientes permite ainda o uso de diálise peritoneal caso necessário.

Nos casos em que o paciente é tratado com transplante duplo de rim e pâncreas, a utilização de duas incisões (uma pra cada órgão transplantado) contribui para aumentar a morbidade do procedimento. Há pouco tempo, uma inovação técnica simples permitiu o transplante dos dois órgãos por meio de uma única incisão mediana, melhorando significativamente o desconforto no período pós operatório imediato e reduzindo o tempo de cirurgia?.

Uma das complicações do transplante renal é a fístula urinária cuja incidência em nosso serviço temse mantido por volta de $2 \%$ a $3 \%$. Seu tratamento, até no passado recente, era feito em etapas. Primeiro ressecava-se o segmento ureteral necrótico, ligandose o ureter proximal do rim transplantado além de fazer uma derivação urinária externa, geralmente uma nefrostomia. Numa segunda etapa, após 3 meses, reoperava-se o paciente para fazer a correção definitiva. Acreditava-se que, com isso, o sucesso da reconstrução seria maior pois os tecidos usados estariam livres de infecção e perfeitamente vitalizados. A desvantagem deste tipo de abordagem é o tempo de espera até a solução final e a dificuldade técnica durante a reoperação devido à fibrose local. A maioria das fístulas urinárias (93\%) são conseqüência de necrose ureteral e cerca de $7 \%$ são devidas a falhas técnicas, não havendo diferença se o doador era vivo ou falecido ${ }^{8}$. O tratamento consiste da anastomose do ureter ou da pelve do rim transplantado com o ureter 
Antonopoulos IM et al. Contribuições à técnica cirúrgica em transplante renal - HC/FMUSP.

primitivo ou, em casos selecionados, no reimplante do ureter na bexiga. O procedimento é bem sucedido em $76,5 \%$ dos casos. O uso de drenagem vesical prolongada pode ter sucesso em $57 \%$ dos casos. A anastomose precoce do ureter transplantado com o ureter primitivo é uma boa opção de tratamento das fístulas urinárias quando as condições locais permitem. A ligadura do ureter do rim transplantado associada a nefrostomia deve ser reservada aos casos com condições locais desfavoráveis ou aos pacientes clinicamente instáveis.

A investigação das causas de disfunção do enxerto passa, muitas vezes, pela realização de biópsias do rim transplantado. Embora o ideal seja usar métodos de imagem para guiar a biópsia do rim transplantado, isto não é obrigatório. Se compararmos a qualidade da biópsia levando em conta o número de glomérulos e vasos obtidos quando a mesma é feita por palpação manual ou guiada por ultra-sonografia, verificamos que a biópsia guiada por método de imagem fornece número significativamente maior de microestruturas a serem analisadas. No entanto, o número das mesmas estruturas (glomérulo se vasos) obtido pela biópsia manual é suficiente para o diagnóstico anátomo-patológico havendo igual taxa de complicação entre ambos os métodos. Não existe, portanto, necessidade absoluta de dispor de ultrasonografia para guiar a biópsia do rim transplantado ${ }^{9}$. O seu valor fica mais evidente nos casos de nova biópsia ou em paciente obesos.

Um problema freqüente nos pacientes transplantados é o tratamento de hérnias incisionais. Nos pacientes não transplantados, o tratamento cirúrgico destas condições passa obrigatoriamente pelo uso de telas de material sintético para reforçar a parede. Nos pacientes transplantados, sempre se temeu o uso de próteses desta natureza pelo receio de haver infecções de parede associadas à presença de um corpo estranho, que poderia colocar em risco o enxerto ou a vida do paciente. A incidência de hérnias incisionais na UTR é de 3,8\% sendo que a maioria ocorre nos primeiros 3 meses de transplante ${ }^{10}$. Utilizando-se a técnica de fechamento por reaproximação primária da aponeurose original do paciente seguida de reforço "on-lay" com tela de polipropileno resulta na resolução do problema com complicações mínimas.

As herniações no paciente transplantado representam um desafio adicional naqueles casos em que infecção ou contaminação da ferida cirúrgica estão presentes. Teoricamente a colocação de telas na tentativa de corrigir o problema poderia resultar no agravamento do mesmo, pois a própria prótese poderia abrigar bactérias, perpetuando o processo infeccioso e obrigando a sua retirada. Assim sendo, o tratamento dos pacientes nestas condições implicava em esperar a ferida cirúrgica granular, resolvendo a infecção, para apenas então partir para a solução definitiva. Esse processo, via de regra, consumia pelo menos 3 meses para se concretizar, tendo óbvio impacto nos custos e afastamento do paciente de suas atividades normais. Esta conduta foi baseada em experiência desenvolvida no uso de telas em cirurgias contaminadas na urgência do Hospital das Clínicas da Faculdade de Medicina da USP, que passou a tratar primariamente os receptores com hérnia e contaminação da incisão abreviando a evolução de 3 meses para menos de duas semanas ${ }^{11}$. $\mathrm{Na}$ UTR a incidência de hérnias incisionais infectadas ou contaminadas chega a 2,8\%. Esses casos podem ser tratados com fechamento primário da parede por reaproximação e colocação de tela "on-lay". É preciso, no entanto, cuidados adicionais. A ferida deve ser exaustivamente lavada com soro fisiológico. Antibióticos de amplo espectro são utilizados por via parenteral e drenos de grosso calibre são usados no leito cirúrgico. Usando esta técnica os drenos são retirados em média após 9 dias (variação 2 a 30 dias) permitindo que o médico dê alta ao paciente. O índice de recidiva é perfeitamente aceitável sendo de $9 \%$.

Como foi mencionado, o rastreamento de doenças como o câncer de próstata passaram a ser feitas apenas mais recentemente, provavelmente por excesso de concentração das equipes médicas no transplante renal propriamente dito. Outra razão para isso é o aumento da sobrevida dos enxertos e dos pacientes transplantados fazendo com que mais pacientes homens entrem na faixa de risco para o câncer de próstata. A indicação mais abrangente de rastreamento ativo para câncer de próstata levou ao aumento do número de diagnósticos dessa doença em homens transplantados renais. É discutível na literatura internacional a melhor abordagem cirúrgica para esses casos. Os principais receios referem-se a dificuldades de acesso à próstata pela presença do rim transplantado, à possibilidade de lesão do ureter transplantado e a dificuldade de se aproximar o colo vesical à uretra para a anastomose entre estas duas estruturas. Na verdade, nenhum desses receios tem fundamento, devendo-se empregar a técnica cirúrgica habitual para o tratamento desses pacientes. A única modificação necessária é a não realização de linfadenectomia do lado do enxerto para evitar a lesão do mesmo ${ }^{12}$. A anastomose uretro vesical é feita sem dificuldades, as complicações cirúrgicas não apresentam diferença em relação aos homens não transplantados e não existe, em absoluto, necessidade sequer de identificação do ureter transplantado. A cirurgia, portanto, pode inclusive ser feita por cirurgião não treinado em transplante renal. 
Uma outra situação desafiadora é a abordagem dos pacientes com pielonefrites de repetição por refluxo vesico-ureteral para o rim transplantado, de ocorrência não muito freqüente mas que, quando presente, associa-se ao risco tanto para o enxerto como para a vida do paciente. A cura do refluxo nesses casos, classicamente feita por via aberta, constitui-se num tratamento de alto risco (devido à fibrose que envolve o rim transplantado) e alto custo (devido ao tempo de internação). Num estudo inicial, avaliamos 8 pacientes com refluxo e pielonefrite associada que foram submetidos a injeção sub-ureteral de agente formador de volume (Durasphere $®$, Carbon Medical Technologies Inc, Minnesota - USA) para tratamento endoscópico do refluxo transformando um procedimento de 4 horas de duração e uma semana de internação em outro de 15 minutos e com apenas um dia de internação. A taxa de cura da infecção de repetição foi de $87,5 \%{ }^{13}$.

Antonopoulos IM, Piovesan AC, Falci Jr. R, Kanashiro H, Saito FJ, Nahas WC. Contributions to the surgical techniques of kidney transplantation - Clinic Hospital of São Paulo University School of Medicine. Rev Med (São Paulo). 2009 jul.-set.;88(3) ed. especial:163-7.

\begin{abstract}
Is not rare to hear that, on kidney transplantation, improvements on surgical aspects are not probable anymore. Although, solutions with high economical impact arises frequently and, many of them, in Brazil, contributing, significantly, for changes on surgical conduct on kidney transplantation worldwide. The surgical techniques for kidney transplantation are well established and do not change between the groups of transplants. Although, the surgical treatment of complicated outcomes and of patients with diseases related to chronic renal failure is still controversial. This study aims to offer a general overview about the surgical techniques of kidney transplantation, complications inherent to this procedure and the results obtained by the Kidney Transplantation Team of Clinic Hospital of São Paulo University Medical School.
\end{abstract}

KEY WORDS: Kidney transplantation. Urologic surgical procedures/methods. Urology department, hospital. Renal insufficiency, chronic/surgery. Hospitals, teaching.

\section{REFERÊNCIAS}

1. Nahas WC, Lucon AM, Mazzucchi E, Scafuri AG, David Neto E, lanhez LE, Arap S. Kidney transplantation: the use of living donors with renal artery lesions. J Urol. 1998;160(4):1244-7.

2. Nahas WC, Hakim NS, Mazzucchi E, Antonopoulos LM, Eltayar AR, Labruzzo C, Chocair PR, Arap S. Transplantation of horseshoe kidney en bloc. Int Surg. 2000;85(3):272-4.

3. Nahas WC, Mazzucchi E, Arap MA, Antonopoulos IM, Neto ED, lanhez LE, Arap S. Augmentation cystoplasty in renal transplantation: a good and safe option experience with 25 cases. Urology. 2002;60(5):770-4.

4. Nahas WC, Antonopoulos IM, Piovesan AC, Pereira LM, Kanashiro H, David-Neto E, lanhez LE, Srougi M. Comparison of renal transplantation outcomes in children with and without bladder dysfunction. A customized approach equals the difference. J Urol. 2008;179(2):712-6.

5. Nahas WC, Lucon M, Mazzucchi E, Antonopoulos IM, Piovesan AC, David Neto E, lanhez LE, Arap S. Clinical and urodynamic evaluation after ureterocystoplasty and kidney transplantation. J Urol. 2004;171(4):1428-31.

6. Nahas WC, Mazzucchi E, Scafuri AG, Antonopoulos I, David Neto E, lanhez LE, Arap S. Extraperitoneal access for kidney transplantation in children weighing $20 \mathrm{~kg}$. or less. J Urol. 2000;164(2):475-8.

7. Piovesan AC, Nahas WC, Antonopoulos IM, Mazzuchi
E, Cocuzza MS. Complete extraperitoneal approach for kidney implant on simultaneous pancreas and kidney transplantation by midline incision. Transplantation. 2006;82(11):1552-4.

8. Mazzucchi E, Souza GL, Hisano M, Antonopoulos IM, Piovesan AC, Nahas WC, Lucon AM, Srougi M. Primary reconstruction is a good option in the treatment of urinary fistula after kidney transplantation. Int Braz J Urol. 2006;32(4):398-403.

9. Antonopoulos IM, Nahas WC, Mazzucchi E, lanhez LE, Saldanha LB, Arap S. Comparison of palpation-guided and ultrasound-guided biopsies in transplanted kidneys. Clin Transplant. 2001;15(6):393-6.

10. Mazzucchi E, Nahas WC, Antonopoulos IM, lanhez LE, Arap S. Incisional hernia and its repair with polypropylene mesh in renal transplant recipients. J Urol. 2001;166:816-9.

11. Antonopoulos IM, Nahas WC, Mazzucchi E, Piovesan AC, Birolini C, Lucon AM. Is polypropylene mesh safe and effective for repairing infected incisional hernia in renal transplant recipients? Urol. 2005;66:874-7.

12. Antonopoulos IM, Nahas WC, Piovesan AC, Falci Jr R, Kanashiro H, Alvarez GA, Srougi M. Radical retropubic prostatectomy for localized prostate cancer in renal transplant patients. Urology. 2008;72:1362-5.

13. Antonopoulos IM, Piovesan AC, Falci Jr R, Kanashiro $\mathrm{H}$, Srougi M, Nahas WC. Anais do Congresso da American Urological Association, Chicago, 2009. 